\title{
TECNOLOGIAS DE INFORMAÇÃO E COMUNICAÇÃO NO CONTEXTO EDUCACIONAL: UMA PERSPECTIVA CRÍTICA
}

\section{INFORMATION AND COMMUNICATION \\ TECHNOLOGIES IN THE EDUCATIONAL CONTEXTO: A CRITICAL PERSPECTIVE}

\begin{abstract}
VERGNA, MÁRCIA APARECIDA
DOUTORANDA EM EDUCAÇ̃̃O NA LINHA DE PESQUISA TECNOLOGIAS DE INFORMAÇ̃̃O E COMUNICACÃO NOS PROCESSOS EDUCACIONAIS, UNIVERSIDADE ESTÁCIO DE SÁ, COM BOLSA DA CAPES/PROSUP.

MESTRADO EM GESTÃO SOCIAL, EDUCAÇÃO E DESENVOLVIMENTO REGIONAL,

GRADUADA EM LETRAS (PORTUGUÊS E INGLÊS) E ESPECIALISTA EM LÍNGUA PORTUGUESA E

LITERATURA BRASILEIRA.

MARCIAVERGNA@YAHOO.COM.BR

ORCID ID: HTTPS://ORCID.ORG/0000-0002-3919-272X
\end{abstract}

\section{RESUMO}

Tem-se observado um discurso crescente acerca da necessidade de utilização de tecnologias digitais de informação e comunicação no espaço escolar, quer seja para o desenvolvimento de competências e habilidades relacionadas a práticas da cultura digital, quer seja para a melhoria dos processos educacionais. A partir de uma perspectiva crítica, este artigo objetiva refletir sobre a integração dos artefatos digitais na educação, tendo como aporte teórico, principalmente, os estudos de Neil Selwyn. Após as reflexões, infere-se que, na atualidade, muitas vezes, tem-se atribuído à tecnologia centralidade no processo educacional, em detrimento da dimensão humana, posicionando o professor, como mero coadjuvante no processo de ensino aprendizagem, creditando ao artefato tecnológico a garantia de uma educação de qualidade. Espera-se que o estudo possa contribuir para suscitar outras reflexões sobre educação e artefatos tecnológicos digitais no contexto educacional.

Palavras-chave: Educação; Perspectiva crítica; Tecnologias de informação e comunicação. 


\section{ABSTRACT}

There has been a growing discourse about the need to use digital information and communication technologies in the school space, whether for the development of competences and skills related to digital culture practices, or for the improvement of educational processes. From a critical perspective, this article aims to reflect on the integration of digital artifacts in education, having as theoretical support, mainly, the studies of Neil Selwyn. After reflections, it is inferred that, nowadays, technology has often been attributed centrality in the educational process, to the detriment of the human dimension, positioning the teacher as a mere supporting role in the teaching-learning process, crediting the technological artifact with the guarantee of quality education. It is hoped that the study can contribute to raise other reflections on education and digital technological artifacts in the educational context.

Keywords: Critical perspective; Education; Information and communication Technologies.

\section{INTRODUÇÃO}

Nas últimas décadas, as tecnologias de informação e comunicação têm implicado grandes e rápidas mudanças nas formas de interação e comunicação das pessoas, estando presentes nos mais diversos segmentos da sociedade e, inclusive, nas escolas, o que tem suscitado estudos e debates: há os que defendem veementemente o seu uso, há os que discutem os processos de disputa de significado em torno dessas tecnologias e, há os que as refutam completamente.

Contudo, tem-se observado, nos últimos anos, um crescente desenvolvimento de políticas públicas e programas governamentais no país visando expandir a inserção desses artefatos digitais no espaço escolar, o que requer um certo cuidado e olhar crítico, pois por trás do incentivo ao uso massivo dessas tecnologias pode-se esconder a ideologia de um governo bem como evidenciar interesses corporativos que poderão afetar toda a sociedade, ocasionando mudanças de ordem social, econômica, política e cultural. Assim, como ocorreu com todas as tecnologias de comunicação do passado, novos artefatos digitais são associados a mudanças na língua, no letramento, na educação e na sociedade.

A partir de uma perspectiva crítica, este artigo objetiva refletir sobre a integração dos artefatos digitais na educação. Inicialmente, 
conceituaremos a perspectiva crítica, posteriormente teceremos as reflexões e, por fim, as considerações finais.

\section{CONCEITUANDO A PERSPECTIVA CRÍTICA}

Selwyn (2017) considera que para se adotar uma perspectiva crítica é necessário problematizar a tecnologia, reconhecendo a necessidade de se questionar seu uso na educação; abordar questões políticas e de poder, revelando as dimensões ideológicas da tecnologia educacional; chamar atenção para os silêncios e o que é silenciado, evidenciando as liberdades e aprisionamentos que estão associados ao uso da tecnologia; objetivar melhoria, uma vez que não faz sentido negarmos a existência da tecnologia digital; pensar de outra forma, transformando a crítica e o conhecimento em produção de estratégias alternativas.

Quando se fala em problematizar a tecnologia consiste em tratála não como um problema e sim em reconhecer a necessidade de se questionar o seu uso na educação, olhando-a com um certo ceticismo, visualizando-a não como ruim, mas como perigosa, exigindo-se, portanto, cautela, pois negar a sua utilização na educação é ir na contramão da história.

Já a abordagem a questões políticas e de poder refere-se à compreensão da dimensão ideológica, que funda o discurso de uso desses artefatos na educação, revelando questões de poder, controle, conflito e resistência, desmistificando o caráter neutro das tecnologias, desafiando os significados e compreensões dos discursos hegemônicos acerca desses artefatos, expondo como as tecnologias disseminam ideias sobre as estruturas econômicas e políticas, descrevendo como determinados "[...] posicionamentos são desenvolvidos, legitimados, reproduzidos e desafiados" (SELWYN, 2017, p. 20).

Além disso, um outro pressuposto, chamar a atenção para os silêncios e o que é silenciado, consiste em mostrar as desvantagens, desigualdades e injustiças que perpassam o discurso da tecnologia no contexto educacional, evidenciando as liberdades e aprisionamentos que estão associados ao seu uso, mostrando como esses artefatos contribuem para fortalecimento e sustentação das estruturas dominantes de produção e poder na educação. Assim, é necessário reconhecer "[...] o papel que a tecnologia exerce em perpetuar as desigualdades existentes na educação, bem como estabelecer novas formas de divisão e desvantagem (SELWYN, 2017, p. 20).

Estudos críticos objetivam também a melhoria, pois "adotar uma 
perspectiva crítica em relação à educação e à tecnologia é um exercício construtivo, e não destrutivo" (SELWYN, 2017, p. 20). O autor afirma que em pleno século XXI não faz o menor sentido sermos contra ou a favor da tecnologia. Seria o mesmo caso de irmos contra ou a favor da comida. Os artefatos digitais já fazem parte do nosso cotidiano, cabenos então a tarefa de apontar eventuais falhas, evidenciando possíveis alternativas para corrigi-las, a fim de tornar a educação e a tecnologia melhores do que são hoje. E, por último, o pressuposto pensar de outra forma, consiste em transformar a crítica e o conhecimento em produção de estratégias alternativas para melhores práticas.

Ressaltamos que não há teoria ou escola de pensamento em específico que os justifiquem, todavia, esse posicionamento encontra inspiração e apoio em um conjunto de princípios filosóficos já existentes, como a teoria crítica, desenvolvida na segunda metade do século XIX e ao longo do século XX "[...] como uma forma de contraposição ao poder, à dominação e desigualdade implícitas no crescimento da era industrial, tendo como origem a crítica de Marx ao capitalismo" (SELWYN, 2017, p. 22). Essa teoria pode "[...] ser vista como uma tentativa de manter a relevância da ideias de Marx do século XIX em uma era subsequente de capitalismo gerencial, burocracia estatal, e aumento da manipulação corporativa do trabalho e da vida social" (SELWYN, 2017, p. 22).

A teoria crítica alinha-se ao surgimento da sociedade digital, e teve origem no trabalho da Escola de Frankfurt, como por exemplo, nos trabalhos de Adorno, Habermas, Marcuse e Horkheimer. "Esses teóricos (e seus seguidores) posicionaram a tecnologia como um conjunto de práticas e processos profundamente políticos, compreendidos em termos de poder e controle" (SELWYN, 2017, p. 23). Para eles, é necessário encontrar as contradições internas entre o que se defende e o que se faz em termos práticos, evidenciando as contradições nas regras e nos processos necessários à produção das formas dominantes de poder e controle.

Somam-se a essa teoria os trabalhos de Michel Focault, no que tange aos seus escritos sobre tecnologia e poder, em que o autor trata das questões da disciplina, (auto) regulação, governamentabilidade e relações entre conhecimento, poder e controle social, bem como de trabalhos de Gilles Deleuze sobre a natureza interconectada da vida cotidiana, e a importância do afeto. Além disso, há também fortes contribuições de teorias feministas, pós-colonialistas, sócio materialistas e pós-humanistas (SELWYN, 2017). 
Pesquisas críticas em educação e tecnologia são consideradas marginais quando comparadas à produção acadêmica nessa área. Normalmente, o que se vê, são trabalhos que abordam a tecnologia na educação como se fosse um caminho óbvio a ser seguido, indo ao encontro do senso comum de que é necessário usá-la na educação, não importando para quê. O que se percebe é uma naturalização do discurso em relação aos supostos benefícios das tecnologias de informação e comunicação para a educação. Antônio Gramsci, filósofo italiano, considera que o senso comum é "[...] um tipo legítimo de conhecimento que construímos ao longo de nossas vidas, mesmo que essa construção ocorra de forma assistemática e informal" (OLIVEIRA, 2013, p. 19).

Nesse sentido, "[...] somos confrontados por um forte sentimento de que o uso da tecnologia na educação é algo que não merece escrutínio ou pensamento crítico em especial" (SELWYN, 2016). Porém, devemos sempre desconfiar da forma de pensar do senso comum uma vez que este pode mascarar, ofuscar ou dissimular problemas reais, silenciando possíveis indagações, podendo ser "profundamente enganoso" (SELWYN, 2016; HARVEY, 2005). Ademais, "o senso comum é um agregado caótico de concepções disparatadas, podendo se encontrar nele tudo o que se queira" (GRAMSCl, 1986, p. 146).

Portanto, problematizar a tecnologia não consiste em visualizá-la como um problema, e sim reconhecer a necessidade de se questionar o seu uso na educação, apreendendo os significados e práticas que a rodeia, bem como relações sociais e estruturas às quais a tecnologia se liga. "Sem dúvida, essa postura continuará a representar uma posição minoritária, sendo que muitos educadores irão continuar a considerá-la um contrassenso e talvez, até mesmo equivocada" (SELWYN, 2017, p. 36), porém, é um trabalho importante que precisa ser realizado.

Assim, o estudo crítico objetiva a superação do discurso do senso comum, da naturalização dos discursos peremptórios acerca das benevolências dos artefatos tecnológicos para educação, fazendo emergir o que é ocultado. Ressalta-se que ter consciência crítica é uma condição essencial para que possamos engendrar as transformações sociais necessárias (OLIVEIRA, 2013), caso contrário estaremos perpetuando os discursos hegemônicos e, consequentemente, contribuindo para manter as relações de poder vigentes que são instauradas por meio dos discursos.

\section{TECNOLOGIAS DE INFORMAÇÃO E COMUNICAÇÃO E EDUCAÇÃO}

Ao longo da história, o homem tem se utilizado de diferentes 
tecnologias para tentar melhorar sua vida. "Em um nível básico, 'tecnologia' é compreendida como o processo pelo qual o humano modifica a natureza para satisfazer suas necessidades e anseios" (SELWYN, 2016, p. 14). Esse uso começou há muitos anos, com o próprio surgimento da humanidade, quando da conversão de recursos naturais em ferramentas simples pelo homem objetivando adaptar-se e controlar o seu meio ambiente, tendo em vista questões de sobrevivência e domínio.

A palavra tecnologia advém do Grego Antigo, e

A primeira metade da palavra, 'techné' pode ser traduzida como habilidade, arte ou ofício. Isso, em si, reflete um prefixo Indo-europeu mais antigo, 'teks', que se refere ao processo de tecer ou fabricar (como na palavra 'têxtil'). A segunda parte do termo remete ao sufixo grego 'logia', traduzido como "a compreensão de algo, ou como 'ramo do conhecimento'. Nesse sentido, a palavra 'tecnologia' sempre se referiu a processos e a práticas para se fazer coisas, compreender coisas ou criar conhecimento (SELWYN, 2016, p. 16).

Enquadram-se nesse grupo os hardwares como desktops, notebooks, tablets, lousas interativas, sistemas de simulação; os aparelhos pessoais como smartphones; aparelhos audiovisuais como rádio digital, televisão digital, fotografia digital, vídeo digital; consoles de jogos e máquinas de jogos portáteis; pacotes de software relacionados a 'conteúdo' (programas de simulação, pacotes tutoriais); 'Conteúdo', serviço e aplicativos de web; outros aplicativos de internet (SELWYN, 2016). Essas tecnologias são sistemas baseados em aplicativos de softwares e hardware computacional objetivando produzir, manipular, armazenar, comunicar e disseminar informação (SELWYN, 2016). Assim, estamos falando não apenas de artefatos, mas de sistemas e processos que levam a resultados desejados.

Desde o lápis até o computador o homem vem utilizando tecnologia na educação, e, em especial, nas últimas décadas, as tecnologias de informação e comunicação. Nesse sentido, elas têm ganhado grande visibilidade no cenário educacional brasileiro, em parte, devido ao incentivo ao seu uso como estratégia para resolver questões educacionais discutidas nos Fóruns Mundiais de Educação. Para Rosado, Ferreira 
e Carvalho (2017), os problemas a que as pessoas, de maneira geral, atribuem à tecnologia a capacidade de "consertar", referem-se desde a falhas cognitivas, dificuldades na aprendizagem até à exclusão social e desigualdade.

Em 1990, vários países, inclusive o Brasil, estiveram reunidos no Fórum Mundial de Educação de Jomtien, Tailândia, onde lá estabeleceram o compromisso Educação para Todos, definindo os rumos da educação mundial e como princípio de ação para se atingir as metas estabelecidas para o decênio já se previa a utilização de artefatos digitais para tentar sanar os problemas educacionais. Para os governos, organizações, agências, grupos e associações que lá estiveram presentes,

A qualidade e a oferta da educação básica podem ser melhoradas mediante a utilização cuidadosa das tecnologias educativas. Onde tais tecnologias não forem amplamente utilizadas, sua introdução exigirá a seleção e/ ou desenvolvimento de tecnologias adequadas, aquisição de equipamento necessário e sistemas operativos, a seleção e treinamento de professores e demais profissionais de educação aptos a trabalhar com eles. A definição de tecnologia adequada varia conforme as características de cada sociedade e poderá mudar rapidamente, na medida em que as novas tecnologias (rádio e televisão educativos, computadores e diversos auxiliares audiovisuais para a instrução) se tornem mais baratas e adaptáveis aos diversos contextos. O uso da tecnologia moderna também permite melhorar a gestão da educação básica. Cada país deverá reavaliar periodicamente sua capacidade tecnológica presente e potencial, em relação aos seus recursos e necessidades básicas educacionais (UNICEF, 1990).

Uma década depois, no ano 2000 mais de 180 países, inclusive o Brasil, estiveram reunidos no Fórum Mundial de Educação de Dakar, Senegal, e lá se ratificou a utilização das tecnologias de informação e comunicação como uma das estratégias para alcançar as metas para a melhoria da educação ofertada devido ao [...] "grande potencial para disseminação do conhecimento, a aprendizagem efetiva e o desenvolvimento de serviços educacionais mais eficientes" (UNESCO, 2001, p. 25). 
Essa mesma importância foi dada às tecnologias também no Fórum Mundial de Educação 2015, realizado em Incheon, na Coreia do Sul em 2015, organizado pela UNESCO, junto com o UNICEF, o Banco Mundial, o UNFPA, o PNUD, a ONU Mulheres e o ACNUR, onde mais de 160 países, incluindo mais de 120 ministros, chefes e membros de delegações, líderes de agências e funcionários de organizações multilaterais e bilaterais, além de representantes da sociedade civil, da profissão docente, do movimento jovem e do setor privado adotaram a Declaração de Incheon para a Educação 2030, estabelecendo uma visão para a educação para os próximos 15 anos, definindo-se, então, o Marco de Ação da Educação 2030, prevendo que as

Tecnologias de informação e comunicação (TIC) devem ser aproveitadas para fortalecer os sistemas de educação, a disseminação do conhecimento, o acesso à informação, a aprendizagem de qualidade e eficaz e a prestação mais eficiente de serviços (UNESCO, 2015).

Dessa forma, esses artefatos foram ganhando espaço na educação, parecendo que "[...] o caminho óbvio para a superação dos problemas sociais contemporâneos envolve, acreditam alguma forma de solução relacionada ao digital (SELWYN, 2016, p. 29). Todavia, é necessário verificar se os problemas a serem sanados podem, de fato, ser resolvidos por meio desses artefatos. Para Selwyn (2016, p. 27),

Uma das características mais impressionantes dos muitos relatos e análises recentes da era digital são as formas em geral "transformatórias" (e frequentemente otimistas) nas quais as mudanças associadas à tecnologia digital tendem a ser imaginadas. Em suma, a maior parte dos relatos sobre a era digital é concebida em termos de discursos de progresso, transformação e sedução "do novo".

Assim, é preciso saber o que de fato pode ser solucionado utilizando os recursos das tecnologias digitais pois "[...] qualquer exemplo de tecnologia na educação precisa ser visto considerando-se os limites e restrições que ela impõem, bem como oportunidades que ela pode oferecer" (SELWYN, 2017, p. 95). O autor ainda afirma que "[...] a possibilidade de a tecnologia não conduzir a aprendizagem ou a outros ganhos educacionais é raramente assunto para consideração" 
(SELWYN, 2017, p. 98). Ora, a quem interessa que não seja assunto para consideração?

Sabe-se que os rumos da educação mundial são definidos por pessoas que são representantes de diversos países bem como de organizações internacionais como a Organização das Nações Unidas (ONU), Banco Mundial, Fundo Monetário Internacional (FMI), a Organização Mundial do Comércio (OMC), dentre outros, e que carregam consigo suas ideologias e objetivos institucionais. Logo, é necessário ter um olhar crítico quando se pretende atrelar melhoria da qualidade educacional às tecnologias de informação e comunicação, pois por trás do incentivo ao uso massivo dessas tecnologias pode-se esconder a ideologia de um governo bem como evidenciar interesses corporativos que poderão afetar toda a sociedade. Para Selwyn (2016, p. 16), essas tecnologias têm "[...] sido entrelaçadas com um conjunto intimamente relacionado de ideologias contemporâneas dominantes ou seja, o libertarianismo, o neoliberalismo e o que pode ser chamado de o 'novo' capitalismo".

Em um sentido popular, o termo 'ideologia" "[...] é mais frequentemente usado para designar um sistema geral de ideias, crenças e valores que orientam a ação" (SELWYN, 2016, p. 4). Fazendo uma análise mais aprofundada do termo, embasando-se em filósofos, o autor pontua que para Karl Marx o conceito de ideologia estava "[...] relacionado com o mascaramento das contradições produzidas pelo sistema capitalista em formas que contribuíam para a sua reprodução" (SELWYN, 2016, p. 5), ocultando assim os padrões reais de poder, sendo dotada de funções políticas, ordenando e orientando o mundo social, legitimando e deslegitimando algumas práticas. Alguns filósofos posteriores a Marx consideram que ideologia está relacionada à dominação de um interesse sobre outros. Nesse sentido,

György Lukáes escreveu sobre ideologia como a consciência individualista das classes burguesas. Por outro lado, Karl Mannheim destacou o potencial pluralista das ideologias a desempenhar um papel central nas tentativas de diferentes grupos de exercer o poder - aumentando, assim, a possibilidade de emergência de sistemas ideológicos em competição a partir de diferentes modos de existência (SELWYN, 2014, p. 8). 
Ideologia também é concebida pelo filósofo Antônio Gramsci como um sistema de ideias, capaz de inspirar atitudes concretas, norteando ações. Assim, é possível que "[...] uma classe exerça 'hegemonia' sobre as outras - isto é, obtenha consentimento para posicionar um sistema de ideias ou 'visão de mundo' como o senso comum da maioria" (SELWYN, 2016, p. 9). Autores contemporâneos, tendem a conceber ideologia como sendo "[...] a manipulação de entendimentos, em uma tentativa de legitimar os interesses de grupos e interesses específicos" (SELWYN, 2016, p. 12). Gramnsci afirma que ideologia corresponde à concepção de mundo dos indivíduos, porém ressalta que em uma sociedade neoliberal nem sempre as concepções de mundo que as pessoas possuem são as mais favoráveis para o conjunto de classes a que pertencem (OLIVEIRA, 2013). Assim,

[...] membros das classes trabalhadoras podem adotar a ideologia capitalista, embora ela não Ihes seja favorável na medida em que os faz se contentarem com uma ínfima parte da riqueza que produzem, cuja maior parte vai para as mãos dos capitalistas (OLIVEIRA, 2013, p. 21).

O que percebemos nos discursos hegemônicos acerca do uso das tecnologias na educação, nos últimos anos, é uma busca desenfreada por atribuir a elas a garantia de uma educação de qualidade, colocandoas em uma posição de destaque, posicionando o professor como mero coadjuvante do processo educacional, fazendo-o conceber a ideologia de que realmente é assim, de que se não usar tecnologia, não importa se é para fazer mais do mesmo, ou seja, repetir velhas práticas, porém agora "novas" usando a tecnologia sem necessariamente ensejar em desenvolvimento de novas competências e habilidades relacionadas a elas, estará defasado, e fadado ao fracasso do processo educacional.

Nesse sentido, na Conferência de Jomtien, em 1990, no relatório da Declaração Mundial sobre Educação afirmava-se que mais de um terço dos adultos não tinham acesso às novas habilidades e tecnologias que poderiam melhorar a qualidade de vida e ajudá-los a perceber e a adaptar-se às mudanças sociais e culturais. Mas por que é necessário que as pessoas tenham acesso às novas tecnologias? A quem interessa que as pessoas tenham equipamentos eletrônicos? Por que introduzir essas tecnologias na escola? Concordamos com Selwyn (2016, p. 38) quando afirma que 
De fato, tecnologias educacionais não são, simplesmente, ferramentas neutras usadas de formas benignas em contextos educacionais. Como quaisquer outras tecnologias, tecnologia educacional está intrinsecamente associada a aspectos sociais, culturais, econômicos e políticos da sociedade.

Assim, para o autor, a tecnologia educacional está associada à ideologia, não sendo, portanto neutra, sendo utilizada a serviço de políticos, formuladores de políticas bem como de empregadores e empresários quealmejam promover mudanças nos sistemas educacionais, muitas vezes a partir de interesses comerciais. É impressionante como parece não ser possível mais ofertar educação sem de alguma forma atrelá-la às tecnologias digitais. E isso fica bem evidente no Marco de ação produzido no Fórum Mundial de Educação realizado recentemente, em 2015, em Incheon, Coreia do Sul onde se definiram os rumos que a educação deve tomar até 2030 e novamente se prevê o uso intensivo das tecnologias de informação e comunicação na educação. Parece-nos que é vista como a mola propulsora do desenvolvimento educacional.

Em âmbito local, esse discurso se materializa nos documentos que regem a educação no país como, por exemplo, a Lei de Diretrizes e Bases da Educação Nacional (LDB), o Plano Nacional de Educação (PNE), lei no 13.005, de 25 de junho de 2014, e a Base Nacional Comum Curricular (BNCC) aprovada recentemente para os ensinos fundamental e médio.

Nesses documentos, como no caso do PNE, os artefatos digitais são vistos como estratégias para se fomentar a qualidade da educação básica em todas as etapas e modalidades. O documento prevê

7.12) incentivar o desenvolvimento, selecionar, certificar e divulgar tecnologias educacionais para a educação infantil, o ensino fundamental e o ensino médio e incentivar práticas pedagógicas inovadoras que assegurem a melhoria do fluxo escolar e a aprendizagem, assegurada a diversidade de métodos e propostas pedagógicas, com preferência para softwares livres e recursos educacionais abertos, bem como o acompanhamento dos resultados nos sistemas de ensino em que forem aplicadas; (BRASIL, 2014).

Também na Base Nacional Comum Curricular, que deverá ser 
implementada até 2020 em todas as instituições de ensino na Educação Infantil e no Ensino Fundamental, e até 2022, no Ensino Médio, a tecnologia ganha destaque com o desenvolvimento de competências e habilidades relacionadas a ela, como as competências 4 e 5 :

4. Utilizar diferentes linguagens - verbal (oral ou visualmotora, como Libras, e escrita), corporal, visual, sonora e digital -, bem como conhecimentos das linguagens artística, matemática e científica, para se expressar e partilhar informações, experiências, ideias e sentimentos em diferentes contextos e produzir sentidos que levem ao entendimento mútuo.

\section{$[\ldots]$}

5. Compreender, utilizar e criar tecnologias digitais de informação e comunicação de forma crítica, significativa, reflexiva e ética nas diversas práticas sociais (incluindo as escolares) para se comunicar, acessar e disseminar informações, produzir conhecimentos, resolver problemas e exercer protagonismo e autoria na vida pessoal e coletiva" (BRASIL, 2018).

Questões ideológicas também podem ser percebidas, por exemplo, quando da escolha das palavras. A linguagem utilizada no dia-a-dia, para designar as mais diferentes formas de ser e de estar no mundo, é muito importante, uma vez que a escolha lexical diz muito da maneira de as pessoas agirem, se comportarem e executarem as inúmeras tarefas, inclusive as formas de conduzirem a educação enquanto prática pedagógica e enquanto política educacional por meio dos discursos presentes nos documentos oficiais.

"Nesse contexto, têm ganhado força rótulos que parecem sustentar, de diferentes maneiras, a fragmentação das práticas da educação" (LEMGRUBER; FERREIRA, 2018, p. 9). Esses rótulos podem ser compreendidos, de acordo com os autores, como metáforas fundamentais. Embasando-se na teoria da argumentação ou nova retórica de Chaïm Perelman, acreditam que "Vivemos por metáforas, elas nos constituem, na medida em que nossas percepções são - em muito balizadas por elas" (LEMGRUBER; FERREIRA, 2018, p. 4). Portanto, o 
uso das metáforas, não no sentido poético, mas no da retórica servem para estruturar o pensamento, expressando diferentes concepções de educação (LEMGRUBER, 2009), consequentemente, de ideologias.

Nessa perspectiva, percebe-se que "[...] as metáforas que perpassam muitas das propostas da tecnologia educacional focalizam, primordialmente, coisas, em detrimento do humano e, sobretudo, de questões relativas a diferenças contextuais e/ou culturais" (FERREIRA; LEMGRUBER, 2018, p. 8). Nos discursos hegemônicos, metáfora muito recorrente na educação é o de se referir às tecnologias de informação e comunicação como sendo ferramentas, sugerindo que algo precisa ser consertado e se deve utilizá-las para isso, promovendo assim a "[...] substituição (parcial ou total) de aspectos humanos da educação por máquinas, a partir da concepção de tecnologia como solução de problemas" (LEMGRUBER; FERREIRA, 2018, p. 9).

Também têm-se atribuído ao professor o rótulo de mediador ou facilitador do processo de ensino e aprendizagem, promovendo um deslocamento de sua função, dando às tecnologias centralidade nas políticas educacionais, alocando-as "[...] na posição de agentes, como se fossem o sujeito das formulações" (BARRETO, 2017, p. 127). Nessa perspectiva, Biesta (2013, p. 32) considera que "Ensinar foi redefinido como apoiar ou facilitar a aprendizagem, assim como a educação é agora frequentemente descrita como propiciadora de oportunidades ou experiências de aprendizagem".

Dessa forma, o professor não é retirado de cena, mas a sua função enquanto profissional da educação é reduzida, muitas vezes sendo restrita apenas "[...] ao controle do tempo e do contato dos alunos com os materiais disponibilizados" (BARRETO, 2017, p. 128). O papel do professor passa a ser de acompanhamento, facilitação, aconselhamento e apoio da condução do processo de ensino e aprendizagem, esquecendose de que "[...] os profissionais da educação têm um papel crucial a desempenhar no processo de definição das necessidades, porque uma parte importante de sua competência profissional reside nesse ponto [...]" BIESTA (2013, p. 41).

Percebe-se também, no que tange aos discursos proferidos sobre a educação, que "[...] a linguagem da educação tem sido em grande parte substituída por uma linguagem da aprendizagem" (BIESTA, 2013, p.30). O autor acredita que as novas teorias da aprendizagem, como por exemplo, as construtivistas e socioculturais, bem como o pósmodernismo, a explosão silenciosa da aprendizagem adulta e a erosão 
do Estado de bem estar-social é que também possibilitaram a criação dessa nova linguagem da aprendizagem. Para Biesta (2013, p. 29-30), "[...] a linguagem importa para a educação, porque a linguagem - ou as linguagens - existente para a educação influencia em grande medida o que pode ser dito e feito, e também o que não pode ser dito e feito."

Esses discursos, ao ressignificarem o conceito de educação, transformando em aprendizagem, acabam, muitas vezes, por restringirem o papel do professor e o da escola, pois a aprendizagem é apenas um componente da educação e não o fim em si mesma. Quando se fala em educação, fala-se em formação humana, ética, social, ou seja, formação em seus diferentes aspectos, enquanto que a aprendizagem é mais focada no indivíduo, reverberando também uma ideologia mais calcada em relações de mercado, onde "Alunos e estudantes se tornaram aprendentes, e a educação adulta se tornou aprendizagem adulta" (BIESTA, 2013, p. 32).

O discurso da necessidade de uma aprendizagem de vida inteira, ou seja, a criação de uma sociedade aprendente, também tem sido enfatizado pelos governos. "'Aprendizagem' tornou-se também um conceito favorito em documentos de políticas nacionais e internacionais [...]" (BIESTA, 2013, p. 32), fazendo, segundo Ball (2013), com que instituições e governos sejam cada vez menos responsáveis por seus trabalhadores e cidadãos nesses e em outros aspectos.

Ball (2013, p.144) acredita que "A indústria da política da aprendizagem ao longo da vida é moldada e conduzida em diversos níveis e a partir de diferentes locais por uma retórica notavelmente estável e incessantemente repetida" de que a aprendizagem é a chave da prosperidade e que as pessoas devem se instrumentalizar para lidar com as mudanças sociais e econômicas de um mundo que está sempre em transformação. "A necessidade e a inevitabilidade da $A L V$ ' são impulsionadas discursivamente pelas repetitivas colocações acerca das demandas urgentes da globalização" (BALL, 2013, p. 147).

Biesta (2013, p. 37-38) considera que

O principal problema com a nova linguagem da aprendizagem é que ela tem facilitado uma nova descrição do processo da educação em termos de uma transação econômica, isto uma transação em que (1) o aprendente é o (potencial) consumidor, aquele que tem

1 Aprendizagem ao Longo da Vida 
certas 'necessidade, em que (2) o professor, o educador ou a instituição educacional são vistos como o provedor, isto é, aquele que existe para satisfazer as necessidades do aprendente, e em que (3) a própria educação se torna uma mercadoria - uma 'coisa' - a ser fornecida ou entregue pelo professor ou pela instituição educacional, e a ser consumida pelo aprendente.

Com isso, tem-se criado "[...] novas formas de 'entrega' e consumo da educação, o que poderá resultar em uma aprendizagem progressivamente fragmentada" (BALL, 2013. p. 152), promovendo a "[...] padronização dos elementos constitutivos do processo pedagógico" (BARRETO, 2017, p. 136), podendo as tecnologias de informação e comunicação serem utilizadas para esse fim, haja vista que a sociedade está imersa em um mundo permeado por aparatos tecnológicos. Como sugere Barreto (2017, p. 129),

[..] não se trata mesmo de substituir os professores pelas $\mathrm{TIC}^{2}$, mas o trabalho docente pelas TIC, com todas as consequências políticas e práticas, operando mudanças profundas a ponto de reconfigurar todo o processo, da formação ao exercício profissional.

Nessa perspectiva, motivado, dentre outros fatores, pelas transformações oriundas da revolução científica-tecnológica e da chamada economia do conhecimento, tem-se promovido a recontextualização do papel do professor e o da própria educação, reconfigurando papéis e conceitos já consolidados em nossa sociedade, ocasionando transformações que poderão impactar, a longo prazo, a formação humana, promovendo o esvaziamento do conceito de educação ao fazer o deslocamento radical, posicionando, nos discursos sobre o uso das tecnologias no contexto educacional, objetos como sujeitos da educação.

Essa ocorrência da fragmentação, reducionismo e desumanização, que são inconsistentes com uma formação humana mais ampla, também foi sugerida por Lemgruber e Ferreira (2018) ao analisarem as metáforas do Lego e puzzle associadas à tecnologia educacional, concluindo que o mosaico seria uma metáfora mais adequada no posicionamento dos

2 Tecnologias de Informação e Comunicação 
artefatos tecnológicos no processo de ensino e aprendizagem. Freitas (2012) sugere que esse estreitamento das finalidades educativas tem sido motivado por alguns grupos empresariais que vêm impondo um controle ideológico do sistema educacional, objetivando produzir o trabalhador que está sendo esperado nas empresas.

Nesse contexto, Ball (2013) afirma que está se caminhando para a produção de um novo tipo de sociedade, uma sociedade na qual todos possuem um plano de aprendizagem pessoal, redigido e monitorado por um mentor escolhido, na qual aprender é uma atividade sem fim, atribuindo ao indivíduo o sucesso ou o fracasso na condução da aprendizagem ao longo de sua existência, eximindo as instituições e Estado de suas responsabilidades, e como sugere Biesta (2013, p. 52) "[...] parece que a nova linguagem da aprendizagem se ajusta bastante bem à estrutura do pensamento neoliberal." Nesse sentido, para Barreto (2017, p. 127),

\begin{abstract}
A lógica, nesta linha, é de que quanto maior a presença da tecnologia, menor a necessidade do trabalho humano, bem como maior a subordinação real do trabalho ao capital e aos que se valem das tecnologias para ampliar as formas de controle do trabalho e dos seus produtos.
\end{abstract}

Porém, é necessário considerar que a integração das tecnologias de informação e comunicação no campo educacional nem sempre pode criar situações positivas para todas as pessoas, pois tem-se como ponto de partida que todas os indivíduos têm acesso aos recursos tecnológicos, o que não é verdade, desconsiderando assim os diferentes contextos sociais, uma vez que nem todos estão na mesma posição inicial, contribuindo, consequentemente, para gerar ainda mais desigualdade social. Para Ball (2013, p. 150), as pessoas
[...] devem internalizar e assumir as responsabilidade pelas suas necessidades, na mesma medida em que suas histórias pessoais e suas condições sociais para a aprendizagem são eliminadas nesse processo.

Assim, o que se percebe nesses discursos hegemônicos, é que se tem atribuído à tecnologia digital a centralidade na condução da aprendizagem do indivíduo, delegando ao professor um papel de menor importância nesse processo, promovendo a padronização 
dessa aprendizagem, já que há instituições prontas para oferecerem os pacotes educacionais, "[...] objetos e materiais, hardware e software, acompanhados de variações em torno de instruções de uso" (BARRETO, 2017, p. 136), moldando esse indivíduo de acordo com o perfil de pessoa desejável para se ter nas empresas, consequentemente, na sociedade. Para Ball (2013, p. 153), a sociedade tem caminhado para a criação de "[...] um aprendiz sem profundidade, flexível, solitário, alerta e responsável, desprovido de sociabilidade, o exemplo mais bem acabado da mercantilização do social."

Nesse contexto, infere-se que o fato de a tecnologia educacional estar associada à ideologia, não sendo, portanto neutra, sendo utilizada a serviço de políticos, formuladores de políticas bem como de empregadores e empresários que almejam promover mudanças nos sistemas educacionais, muitas vezes a partir de interesses comerciais (SELWYN, 2017) é que tem contribuído também para propiciar esse reducionismo do papel do professor.

Comênio (1995), no século XVII, já propunha, por exemplo, o uso de manuais e livros ao alcance de professores e alunos. Porém, o papel do professor não era reduzido a uma mera engrenagem do processo educacional como se tem apregoado nesses discursos hegemônicos. Para Comênio (1995, p. 460), "[...] quando aos livros se junta a voz do professor (que explica tudo racionalmente, segunda a capacidade dos alunos, e tudo ensina a pôr em prática), tornam-se cheios de vida [...]" entendendo verdadeiramente aquilo que aprendem.

É interessante observar que quando se veiculam na mídia escolas que obtiveram bons desempenhos no Índice de Desenvolvimento da Educação (IDEB), o uso das tecnologias de informação e comunicação fica em segundo plano, o que é apontado como elemento primordial para a aprendizagem dos alunos, é o desempenho, a dedicação do professor. Contudo, na hora de se pensar em políticas de melhoria para a educação se pensa, substancialmente, em tecnologia e pouco no professor.

Assim, é necessário questionar se realmente o problema, a que se atribui à tecnologia digital a capacidade de resolver, é de fato um problema que pode ser solucionado usando essa estratégia, ou se não se trata de algo bem mais complexo que tem ligações profundas com nossa formação histórica e cultural e que precisam ser sanados com políticas que abordem a valorização do profissional da educação, envolvendo questões que vão desde a formação docente e continuada até à questão salarial. 


\section{CONSIDERAÇÕES FINAIS}

Indubitavelmente, é importante "[...] reconhecer a necessidade de se interrogar seriamente o uso da tecnologia na educação" (SELWYN, 2017, p.88), pois pode ser que, além de não resolvermos as questões a que foram propostas, sejam criadas novas situações que irão afetar, de alguma forma, a sociedade em geral, promovendo inclusive, por exemplo, a exclusão digital, haja vista as dificuldades de ordem econômica que afetam milhares de brasileiros. Assim como Michel Foucault acredita que nem tudo é mau, mas que tudo é perigoso, é mister "[...] reconhecer a natureza inerentemente política da educação e tecnologia" (SELWYN, 2017, p.89).

Ao se empregar esses artefatos na educação é importante considerar a possibilidade de serem de fato necessários para um dado contexto bem como a sua efetividade em alcançar resultados que não poderiam ser obtidos utilizando-se de outros meios. Urge ainda a necessidade de se considerar os novos problemas que serão criados com a resolução do problema velho. Assim, "[...] qualquer exemplo de tecnologia na educação precisa ser visto considerando-se os limites e restrições que ela impõe, bem como oportunidades que ela pode oferecer (SELWYN, 2017, p. 95).

Portanto, assim como em "As cidades invisíveis", Calvino (2003, p. 17) afirma que "Os olhos não veem coisas, mas figuras de coisas que significam outras coisas", é importante compreender que outras "coisas" subjazem esses discursos hegemônicos que promovem o uso das tecnologias de informação e comunicação na educação, pois assim como Michel Foucault acredita que nem tudo é mau, mas que tudo é perigoso, é mister "[...] reconhecer a natureza inerentemente política da educação e tecnologia" (SELWYN, 2017, p.89).

\section{REFERÊNCIAS}

BALL, Stephen. Aprendizagem ao longo da vida, subjetividade e a sociedade totalmente pedagogizada. Educação, Porto Alegre, v. 36, n. 2, p. 144-155, 27 jun. 2013. Disponível em: <http://revistaseletronicas.pucrs.br/ojs/index.php/faced/article/view/12886/9446>. Acesso em: 23 jun. 2018.

BANNEL, Ralph Ings Bannell. Uma faca de dois gumes. In: Ferreira, Giselle Martins dos Santos; ROSADO, Luiz Alexandre da Silva; CARVALHO, Jaciara de Sá. Educação e Tecnologia: abordagens críticas. Rio de Janeiro: SESES, 2017.

BARRETO, Raquel Goulart. Objetos como sujeitos: o deslocamento radical. IN: 
FERREIRA, G. M. S.; ROSADO, A.; CARVALHO, J. (Org.) Educação e Tecnologia: abordagens críticas. Rio de Janeiro: SESES/UNESA, 2017. Disponível em: <https://ticpe. files.wordpress.com/2017/04/ebook-ticpe-2017.pdf>. Acesso em: 20 jun 2018.

BIESTA, Gert. Contra a aprendizagem: recuperando uma linguagem para a educação numa era da aprendizagem. In:___ Para além da aprendizagem: educação democrática para um futuro humano. Belo Horizonte: Autêntica Editora, 2013.

BRASIL. Lei no 13.005, de 25 de junho de 2014. Aprova o Plano Nacional de Educação - PNE e dá outras providências. 2014. Disponível em: <http://www.planalto.gov.br/ ccivil_03/_Ato2011-2014/2014/Lei/L13005.htm>. Acesso em: 2 dez 2019.

BRASIL. Base Nacional Comum Curricular: educação é a base. 2018. Disponível em: <http://basenacionalcomum.mec.gov.br/images/BNCC_El_EF_110518_versaofinal_site. pdf>. Acesso em: 2 dez 2019.

CALVINO, Italo. (2003). Cidades Invisíveis. Rio de Janeiro: Ed. Globo. TRECHOS.

COMÊNIO, João Amós. Didactica Magna. Lisboa, Calouste Gulbekian, 1995. TRECHOS.

FERREIRA, Giselle Martins dos Santos; LEMGRUBER, Márcio Silveira. Tecnologias educacionais como ferramentas: considerações críticas acerca de uma metáfora fundamental. Arquivos Analíticos de Políticas Educativas, Arizona State University v. 26, n. 112. set/2018. Disponível em: <http://dx.doi.org/10.14507/epaa.26.3864>. Acesso em: 12 dez 2019.

FREITAS, Luiz de Carlos. Os reformadores empresariais da educação: da desmoralização do magistério a destruição do sistema público de educação. Educação e Sociedade, Campinas, v. 33, n. 119, p. 379-404, abr.-jun. 2012

GRAMSCI, Antônio. Concepção Dialética da História. Rio de Janeiro: Civilização Brasileira, 1986.

HARVEY, David. O neoliberalismo: história e implicações. Inglaterra: Edições Loyola. 2005.

LEMGRUBER, Márcio. Argumentação, metáforas e labirintos. Educação e Cultura Contemporânea, Rio de Janeiro, v. 6, n. 13, p. 155-172, 2009.

LEMGRUBER, Márcio; FERREIRA, Giselle Martins dos Santos. Metáforas Fundamentais da Tecnologia Educacional. Educ. foco, Juiz de Fora, v. 23, n. 1, p. 15-38, jan/abr 2018. Disponível em: <file://C:/Users/Usuario/Downloads/20012-Texto\%20do\%20 artigo-81179-5-10-20190730\%20(2).pdf>. Acesso em: 4 out 2019.

OLIVEIRA, Luciano Amaral de. Gramsci. In: OLIVEIRA, Luciano Amaral de (org.). Estudos do discurso: perspectivas teóricas. São Paulo: Parábola Editorial, 2013.

ROSADO, Luiz Alexandre da Silva; FERREIRA, Gisele Martins dos Santos; CARVALHO, 
Jaciara de Sá. Educação e tecnologia na literatura acadêmica on-line em português. In: Ferreira, Giselle Martins dos Santos; ROSADO, Luiz Alexandre da Silva; CARVALHO, Jaciara de Sá. Educação e Tecnologia: abordagens críticas. Rio de Janeiro: SESES, 2017.

SELWYN, Neil. Educational technology as ideology. In: SELWYN, N. Distrusting Educational Technology. Londres: Routledge, 2014. Edição para Kindle. Tradução para o português de Giselle M. S. Ferreira: "Tecnologia educacional como ideologia", 2016. Disponível em: <https://ticpe.files.wordpress.com/2016/12/neil_selwyn_distrusting_ cap2_trad_pt_final.pdf>. Acesso em: 10 jun. 2018.

SELWYN, Neil. What do we mean by 'education' and 'technology'? In: SELWYN, N. Education and Technology: key issues and debates. Londres: Bloomsbury, 2014. Edição para Kindle. Tradução para o português de Giselle M. S. Ferreira: "O que queremos dizer com 'educação' e 'tecnologia'?, 2016. Disponível em: <https://ticpe.files.wordpress. com/2016/12/neil_selwyn_keyquestions_cap1_trad_pt_final1.pdf>. A cesso em: 1 jun. 2018.

SELWYN, Neil. Educação e tecnologia: questões críticas. In: Ferreira, Giselle Martins dos Santos; ROSADO, Luiz Alexandre da Silva; CARVALHO, Jaciara de Sá. Educação e Tecnologia: abordagens críticas. Rio de Janeiro: SESES, 2017.

UNESCO (Organização das Nações Unidas para a Educação, a Ciência e a Cultura). Educação para Todos: o compromisso de Dakar, Brasília: UNESCO, CONSED, Ação educativa, 2001. Disponível em: < https://unesdoc.unesco.org/ark:/48223/ pf0000127509>. Acesso em: 02 dez 2019.

UNESCO. (Organização das Nações Unidas para a Educação, a Ciência e a Cultura). Educação 2030: Declaração de Incheone Marco de Ação para a implementação do Objetivo de Desenvolvimento Sustentável 4. 2015. Disponível em: <https://unesdoc. unesco.org/ark:/48223/pf0000245656_por/PDF/245656por.pdf.multi>. Acesso em: 2 dez 2019.

UNICEF (Fundo das Nações Unidas para a Infância). Declaração Mundial sobre Educação para Todos (Conferência de Jomtien - 1990). 1990. Disponível em:

<https://www.unicef.org/brazil/declaracao-mundial-sobre-educacao-para-todosconferencia-de-jomtien-1990>. Acesso em: 2 dez 2019.

Recebido em: 29/07/2020

Aceito em: 01/12/2020 